Johan, Novie, Sadler-Smith, Eugene and

Tribe, John (2019) Informal and Incidental Learning in the Liminal Space of Extended Independent (Gap-Year) Travel. Academy of Management Learning \& Education, 18 (3). pp. 388-413.

Downloaded from: http://ray.yorksj.ac.uk/id/eprint/4680/

The version presented here may differ from the published version or version of record. If you intend to cite from the work you are advised to consult the publisher's version: http://dx.doi.org/10.5465/amle.2014.0350

Research at York St John (RaY) is an institutional repository. It supports the principles of open access by making the research outputs of the University available in digital form. Copyright of the items stored in RaY reside with the authors and/or other copyright owners. Users may access full text items free of charge, and may download a copy for private study or non-commercial research. For further reuse terms, see licence terms governing individual outputs. Institutional Repository Policy Statement

\title{
RaY
}

Research at the University of York St John

For more information please contact RaY at ray@yorksj.ac.uk 


\section{INFORMAL AND INCIDENTAL LEARNING IN THE LIMINAL SPACE OF EXTENDED INDEPENDENT ('GAP YEAR') TRAVEL}

\section{INTRODUCTION}

Management learning and education research concerns itself mainly with learning that takes place on formal programs of study conducted in business school classrooms (see Armstrong \& Fukami, 2009). However significant student learning experiences also occur informally and incidentally in alternative spaces outside of the walls of business schools and the academic schedule (Marsick \& Watkins, 1990; Marsick \& Watkins, 2001; Marsick \& Volpe, 1999), including encounters with different cultures at significant life junctures. The informal and incidental aspects of learning are potentially powerful but also "problematic" (Caza \& Brower, 2015: 109), they are under-researched and over-simplified (Eraut, 2004), and management learning and education may "not be using their influence as well as [it] might" (op cit., p. 96) hence there is a need both to understand them better and leverage their learning potential.

One such space that is replete with potential opportunities for informal and incidental learning is in the liminality "betwixt and between" (Turner, 1974: 3) high school and higher education, between higher education and full time employment, or during early career stages. The potential for learning in this liminal space is amplified when it involves a significant intercultural component; in our case this is in the form of extended independent overseas travel. Such extended independent overseas travel, also known as 'gap year travel', affords learners invaluable 'time-outs', 'gaps' or 'breaks' in environments which may be very different to those with which they are familiar and which may give rise to novel experiences from which significant informal and incidental learnings may occur. Marking as they do a "transition from one stage of life to the next" (Snee, 2013: 143) liminalities such as the 'gap year' have enhanced potential to afford students and early career professionals learning opportunities in which the assumptions of their formative years - which may have resulted in 
"distorted views of reality" (Mezirow, 1990: 13) — can be reassessed and transformed. The learning processes which this entails may also have wider significance.

The empirical setting of the research is extended independent travel. Extended independent travel (or gap year travel, see below) is unique both as a learning opportunity and as a research focus in that: (a) it presents itself, often for the first time, in early adulthood; (b) it is a novel setting for unusual interpersonal and intercultural encounters and potentially unique learning experiences; (c) the learning experiences of extended independent travel— occurring as they do at critical life junctures and in new and culturally unfamiliar surroundings — are imbued with possibilities both for disorientation and transformation. Moreover, the gap year context is different in kind from other more formalized and structured 'intercultural' learning experiences such as study abroad or international exchange programs (see Background).

Even though management learning and education researchers have examined relationships between cross-cultural exchanges and learning (Li et al., 2013; Mosakowski, Calic \& Earley, 2013; Pless, Maak, \& Stahl, 2011; Yamazaki \& Kayes, 2004) the phenomena of informal and incidental learning in the liminal space of extended independent travel is, to the best of our knowledge, unexplored. Moreover, the study of travel as a focal context for learning is deserving of increased attention (Falk, Ballantyne, Packer, \& Benckendorff, 2012) given that the world is now "dynamically globally interconnected" (Li et al., 2013: 32), there is a proliferation of travel prospects available to young people which present learning opportunities on a scale previously unknown (Stone \& Petrick, 2013). Finally, since young people and their families devote considerable resources to the experience of 'gap year' travel, one must presume they do so in anticipation of some benefit; from the point of view of learning, a legitimate question must be: what are the benefits and how do they arise?

In carrying out this research we sought insights into the informal and incidental learnings which take place when young people purposely undertake extended independent 
Learning in the liminal space of extended independent travel

travel experiences at transitional junctures in early adulthood in culturally unfamiliar spaces (i.e. in a gap year). Our objective was to better understand informal and incidental learning processes and outcomes in the liminal space of extended independent (gap year) travel

\section{BACKGROUND}

The literature review section of our article is organized as follows: extended independent ('gap year') travel; formal learning in intercultural settings; informal and incidental learning; experiential and transformative learning; learning and liminality.

\section{EXTENDED INDEPENDENT ('GAP YEAR') TRAVEL}

The context of our research is extended independent travel, often referred to as gap year travel. The term 'gap year' itself came to prominence in the UK and several other countries (including the Australia, Canada, New Zealand and the United States) in the 1990s and is defined as "any period of time between three and 24 months which an individual 'takes out' of formal education, training or the workplace, and where the time [out] sits in the context of a longer career trajectory" (Jones, 2004: 8). The gap year phenomenon is well-known in the UK, and other Anglosphere cultures have broadly equivalent 'rites of passage' which involve an intercultural component, for example New Zealand's 'big OE' (overseas experience) (for reviews see: Lyons et al., 2012; O’Reilly, 2006; Simpson, 2004).

The key characteristic of a gap year is that it involves no formal study hence it is distinct from the more familiar 'study abroad' or international student exchange programs which, although they have an 'intercultural' component do not involve a 'time-out' from formal study and the learnings which take place are more structured, planned and deliberate. The gap year is a break from the normal course of educational or early career events, but not a "complete rupture" from what comes before and after, instead it is a "liminal period" between life stages (Snee, 2013: 143). The gap year or its equivalent is important in young people's development and transition, as evinced by its popularity for example it is estimated that in the UK "up to 250,000 young people take a gap year each year" and of these 
approximately 45,000 are pre-university (King, 2011: 324).

During their extended period of time abroad gap year travelers, or 'gappers', normally undertake a variety of novel and sometimes challenging activities (for example, sightseeing, working, volunteering, expeditions, extreme sports, adventure activities, as well as rest and relaxation) (Duncan, 2004; Heath, 2007; Jones, 2004; Mintel, 2005; O’Reilly, 2006; Simpson, 2005). The motivations for such ventures have been found to be, in descending order of importance: 'social attraction' (including overseas/family connections), 'exploration' (from boredom/job/relationship), 'personal predisposition', and 'escape' (Inkson \& Myers, 2003). Although it is possible to take a gap year at home (King, 2011) the vast majority (certainly in the case of UK gappers) are taken abroad such that a small segment of the travel industry sector has developed to serve the 'gap year' market (Jones, 2004). Gap year travel is not the same as study abroad or international student exchange programs because it is a timeout from formal education (in the following section we discuss research which has studied learning in different cultures as distinct from gap year travel). As a rite of passage, a gap year presents young people with the opportunities for "freedom, personal development, and fulfilment", a period of "fun and independence before taking on the roles of responsible adulthood" (O’Reilly, 2006: 998), as well as a locus for experiencing transitions in identity during young adulthood (Johan, 2009; King, 2011). It therefore affords researchers a potentially revealing context in which to study informal and incidental learning under conditions of liminality; it is this which sets it apart from more structured and formal learning experiences in intercultural settings.

\section{FORMAL LEARNING IN INTERCULTURAL SETTINGS}

Unlike gap year travel learning, educational scholars have researched the learnings which take place as a result of various types of intercultural experiences, such as study abroad and international student exchange programs which are now part of an increasingly globalized higher education sector (Otten, 2003). For example, Che et al (2009) used the social and 
developmental theories of Vygotsky and Piaget in arguing that 'dissonant experiences' in less familiar destinations are a source of 'constructive disequilibrium' which offers unique opportunities for learning and personal development, including "intercultural maturity" (p. 110). McLaughlin and Johnson (2006) used an experiential learning model to study the learning gains in short-term study abroad courses which 'opened the eyes' of students at important "juncture[s] in their career path" through a real-world "un-buffered" experience (p.76). Bhawuk and Brislin (2000) studied how cross-cultural expertise develops, and Taylor (1994: 154) argued that the acquisition of 'intercultural competency' is an "adaptive capacity based on an inclusive and integrative world view". The studies however offered limited theoretical insights into learning processes and outcomes.

While it is clear that researchers have studied learning in the context of various types of intercultural and planned exchanges experiences, to the best of our knowledge, the in-depth study of the processes of informal and incidental learning during extended independent travel (gap year travel) is under-explored. Gap year travel is important in our research for two main reasons. First, given that gap year travel is a socially significant and distinctive informal intercultural learning experience, it is our contention that understanding the learning that takes place is of theoretical and practical significance. Second, extended independent travel, such as the gap year, is undertaken at a critical life juncture in new, unfamiliar and potentially disorienting surroundings and therefore has high potential to shed light on our phenomenon of interest, i.e. informal and incidental learning processes and outcomes in liminal spaces.

\section{INFORMAL AND INCIDENTAL LEARNING}

Informal learning is typically neither classroom-based nor highly structured, it recognizes the social significance of learning from other people (Boud \& Middleton, 2003) and implies scope for individual agency (Eraut, 2004), whilst incidental learning is a by-product of some other activity (which may be formal or informal) (Marsick \& Watkins, 2001). In the workplace context such learnings could include trial-and-error experimentation, coaching and 
supervision, learning on-the-job or other task-related accomplishments (Marsick \& Watkins, 1990). More broadly, such learning can emanate from interaction with people and places in an environment that is neither configured for nor conducive to learning, moreover it can take place even though people are not always conscious of it at the time (Eraut, 2004; Marsick \& Watkins, 1990). Marsick and Volpe (1999) concluded that informal and incidental learning is: integrated with daily life; not highly conscious; haphazard and influenced by chance; triggered by an internal or external jolt; an inductive process of reflection/action; linked to the learning of others. In these various respects this conceptualisation of informal and incidental learning resonates strongly with the theories of Kolb and Mezirow (see below).

Researchers typically use the lens of work to better understand informal and incidental learning processes and outcomes (Poell, Yorks, \& Marsick, 2009; Raelin, 2000; Scheeres, Solomon, Boud, \& Rooney, 2010). Such studies focus on learning from and through experience, typically involving interactions with others (Boud \& Middleton, 2003; Eraut, 2004; Marsick et al., 2017). However, informal and incidental learning research has not ventured widely outside the confines of work settings. But given that informal and incidental learning processes are highly contextual (Marsick \& Volpe, 1999), it will be instructive to study the phenomenon in a gap year context since this is unique both in terms of the geographical/cultural space in which it occurs (intercultural) and the temporal juncture at which it happens (transitional). Such an endeavor is consistent with the approach of informal and incidental learning research which acknowledges the uniqueness and situatedness of context and process in order to "uncover and unpack what is being learned, how it is being learned and by whom" (Fuller et al., 2003: 5).

\section{EXPERIENTIAL AND TRANSFORMATIVE LEARNING THEORIES}

Kolb's and Mezirow's learning theories resonate with theories of informal and incidental learning in that they accommodate learning that is: triggered by an internal or external 'jolt' resulting in dissonance or disorientation; not highly conscious; often haphazard and 
influenced by chance; an inductive process of reflection and action; linked to learning with and from others (Boud \& Middleton, 2003; Eraut, 2004; Kolb, 1984; Marsick and Volpe, 1999; Mezirow, 1991). Kolb's and Mezirow's theories have been explicated, reviewed and critiqued elsewhere (Cranton, 1994; Dirkx, 2012; Field, 2012; Grabove, 1997; Kayes, 2002; Reynolds \& Vince, 2007; Nohl, 2015; O’Sullivan, Morrell, \& O’Connor, 2002; Taylor, 1997; Taylor \& Cranton, 2013). As far as the review section of our article is concerned we focus on attributes of the experiential and transformative models to the extent that they afford us useful theoretical and analytical resources.

In experiential learning theory, which is well-known in management learning and education (MLE), learning: (a) is a process whereby "knowledge is created through the transformation of experience" (Kolb, 1984: 38); (b) results from synergistic interactions between the person and the environment; (c) requires the resolution of conflicts, differences and disagreements. Since seeking-out and exploring experiences that are novel and have the potential to be uncertain, ambiguous, and risky is one of the chief motivations for gap year travel (Inkson \& Myers, 2003), experiential learning theory's precepts are germane to our research. Furthermore, reflection is an important aspect of the theory such that it is “fundamental to learning" (Raelin, 2001: 11). Kolb's theory is relevant to liminality in that within liminal spaces (or "liminal sections", see van Gennep, 1960, p.94), learners are "granted temporary freedom to explore" (Kolb \& Kolb, 2010: 30), however in moving beyond the familiar, the possibility for discrepant and dissonant experiences and disorientation also exists and frequently presents.

Mezirow (1990: 1) defined learning as "the process of making a new or revised interpretation of the meaning of an experience"; the parallel with Kolb's definition (see [a] above) is palpable. The "fundamental postulate" of Mezirow's theory is that "uncritically assimilated habits of expectation or meaning perspectives serve as schemes and as perceptual and interpretive codes in the construal of meaning" (Mezirow, 1991: 4). In other words, 
habituated perceptions, interpretations and meaning schemes diminish awareness of how things really are; however, events which occur as a result of novel experiences — such as those occurring during travel—are likely to transgress and disrupt the constraints of the 'boundary structures' imposed by habits and meaning schemes. Transformative learning theory accords specific importance to the 'transformation of meaning schemes' through the encountering of anomalies: what are termed 'perspective transformations' occur as a result of the accretion of anomalies and "disorienting dilemmas" which initiate the process of transformation (Mezirow, 1990: 13). The disorienting dilemma is often evoked by an "eyeopening" experience in unfamiliar settings where for example differing social norms prevail and "efforts to understand a different culture challenges one's presuppositions" (op cit.: 14) (see also Nohl, 2014) $)^{1}$.

\section{LEARNING AND LIMINALITY}

'Liminality’ (Turner, 1974; van Gennep, 1909, 1960), as used in cultural anthropology, describes a transitional condition or state between two periods of active social participation (Cook-Sather, 2011) in which novel configurations of ideas and relations may arise (Turner, 1969/1996). Learning and liminality are closely connected (Tempest and Starkey, 2004). Learning under conditions of liminality involves the encountering of something new and unusual, a recognition of shortcomings in the learner's existing view and, consequentially, a 'letting go' (Land et al., 2014). In such learnings, current certainties are engaged with but rendered problematic as a result of experiences that are unsettling and disconcerting (Meyer \& Land, 2005). This may lead to an 'un-doing of scripts' and a 're-authoring of the self' (cf. Mead, 1934); hence liminality has a potentially transformative function (Land et al., 2014; Meyer \& Land, 2005). For examples of the small number of studies of liminality in management in general and in management learning and education, see Hawkins and Edwards (2014); Simpson et al. (2009); Tempest \& Starkey (2004).

We consider extended independent (gap year) travel to be a good exemplar of a 
liminal space, and useful for understanding informal and incidental learning on two counts: first, the separation from the established order (for example, through extended independent travel) affords young people the power and potential to challenge existing norms, values and identities (Cook-Sather, 2011). However, with such liminality comes risk: because the unfamiliar situation is insecure, a young person may find their position no longer fixed but shifting, bringing with it vulnerability and the potential for dissonance and disorientation (Cook-Sather, 2011; Field, 2012; Taylor \& Cranton, 2013); second, liminality also is a useful conceptual tool in understanding the role played in learning by "discrepant [dissonant/disorienting] experiences", that is experiences that are novel, unique, and insecure, and which may contradict past experiences (Taylor \& Cranton, 2013: 37). As a source of dissonance and disorientation (cf. Mezirow's transformative learning theory) the liminal space of extended independent travel — involving as it does new and potentially unsettling cultural and social experiences - has the potential to catalyze learning and transformation in interesting and novel ways. At its most profound level, extended independent travel involves a search for new meanings, an awareness that one can no longer turn back, and the crossing of a threshold into a 'paradoxical' space free of both constraints and certainties (McWhinney \& Markos, 2003). Understood as a rite of passage, extended independent travel includes "pre-liminal rites (rites of separation), liminal rites (rites of transition), and post-liminal rites (rites of incorporation)" (van Gennep, 1909, 1960: 11). In passing from liminality to postliminality learners cross transformative and irreversible thresholds (Meyer \& Land, 2005) and thereby achieve "a new way of understanding, interpreting or viewing the world" (Nahavandi, 2016: 796).

\section{SUMMARY}

In this section of our article we have reviewed several bodies of literature. The novelty of contribution in our work is that it connects several related bodies of learning literature (informal and incidental; experiential; transformative) with a new, but highly relevant, 
context (extended independent, 'gap year', travel) in a way that is distinctive from previous research into the intercultural, and usually more structured and formalized, aspects of learning (e.g., study abroad, international exchange programs) framed within the concept of liminality (conceptualized both in terms of geographical space and temporal juncture). Our research question is: what are the processes and outcomes of informal and incidental learning in the liminal space of extended independent (gap year) travel? In answering this question, we sought to gain insights into how informal and incidental learning beyond the workplace might be theorized and how understandings of these processes might be leveraged to produce beneficial outcomes in the learning and development of young people and early career professionals both inside and beyond the confines of the business school environment.

\section{METHOD}

\section{DESIGN AND SAMPLE}

Data collection was by means of a series of in-depth, semi-structured interviews with a UKbased sample who had undertaken extensive foreign travel. Flyers were distributed to all higher education institutions $(N=114)$ in the South East of England. Based on consensus in the literature of what constitutes a 'gapper' (Jones, 2004; Mintel, 2005), the criteria for final inclusion in the sample were: aged between 17- and 30-years old; embarked on a major overseas travel experience in the form of independent or unorganized travel (before, during, or shortly after higher education); with a three-month to 24-month duration; taken within the 24 months of the research being undertaken (Jones, 2004; Levinson, Darrow, Klein, Levinson \& McKee, 1978; Loker-Murphy \& Pearce, 1995; Mintel, 2005). A sample of 27 participants ('gappers') was recruited using self-selection and snowball sampling (see Appendix 'Sample Characteristics').

The 'independent and unorganized travel' criterion afforded us enhanced potential for unearthing distinctive learning experiences thereby making it more likely that our phenomenon of interest would emerge clearly and cleanly (see: Langley \& Abdallah, 2011). 
The three-month stipulation provided a clear separation between long-term and short-term travel (Jones, 2004), whereas any travel of more than 24-months borders on travelling as a way of living or a form of migration (Teo \& Leong, 2006). Temporal proximity to the actual gap year travel experience was important in sampling and data collection since memories may fade or become distorted resulting in a loss of the depth and richness of the individual's reflection on their experiences militating against a time frame of any longer duration.

\section{DATA COLLECTION}

To achieve the desired breadth and depth of data coverage, each gapper was interviewed twice (approximately 30-60 minutes on each occasion, dependent on the flow and direction of the discussion) using a face-to-face, in-depth, semi-structured format. The participants' experiences were explored in-depth in the first interview using an open-ended conversational style in line with the practice that initial data collection should be relatively open and nonprescriptive thereby maximizing the potential an exploratory discussion (Bryman, 2004). The second interview allowed for follow-up and further discussions that had not been covered or were not ready to be discussed previously, it also allowed for trust and confidence to build and for further recollections of relevant experiences.

The first interview consisted of a 'warm-up' introduction, then the main interview questions and on completion of which there was a closing summary. The principal interview question was "what was the most significant experience during your gap year travel?" (Interpretation of 'significant' was left to participants to determine, with supporting prompts but without interference from the interviewer; see Appendix 'Interview Protocol'). Participants then were invited to elaborate further, e.g. "What do you think has changed for you as a result of that experience?" and "What have you discovered about yourself as a result of this experience?" Dialogue with the researcher (the first-named author) was primarily verbal however during some interviews participants also chose to use pictures, letters, diaries, agendas, blogs, postcards, souvenirs and brochures in order to illustrate their experiences. 
Informed consent, right to privacy and protection from potential emotional impacts (American Psychological Association, 2002) was also practiced to protect participants revealing sensitive issues about their personal lives (Gubrium \& Holstein, 1995).

\section{DATA ANALYSIS}

We used a template analysis strategy (King, 1998) with Kolb's and Mezirow's theories affording us preliminary theoretical frames with which to interpret the data (see Langley, 1999). An obvious potential drawback, which we were alert to, is that such an approach 'brackets' the data interpretation in terms of pre-existing concepts, however we attempted to obviate this by allowing for the emergence of new ideas and insights by going through multiple iterations of re-reading the data. This approach offered the advantage of drawingout trends and relationships in terms of themes which honored prior theory whilst allowing for the emergence of new themes. We created space for conceptual and theoretical adjustment, augmentation and elaboration (Crabtree \& Miller, 1999; Stein, Lauer, \& ElKharbili, 2009). The decision was taken to analyze the data manually so as to maintain the researchers' close connection to the data (Saldana, 2009). While this was undoubtedly effortful and time-consuming, it enhanced our investigative thinking and provided "more control over and ownership of the work" (Saldana, 2009: 22).

In-line with advocated best practice, analysis began "as soon as the first set of transcripts [were] available" (Bryman, 2004: 85); audio recordings of the interviews were transcribed immediately, and was followed by the researchers' deep immersion in the data (Suddaby, 2006). Since the interviewing and data analysis process was iterative, re-coding and re-categorizing throughout the process was necessary (Saldana, 2009) to ensure consistency in application of the approach for all participants and across both interviews. After all the transcripts from both interviews were reviewed several times, they were coded initially using the template approach. Interviews were terminated at the $27^{\text {th }}$ interview as data, theoretical, and thematic saturations that afforded adequate answers to the research 
objectives were judged to have been reached (King, 1998; Marshall, 1996; Robson, 2002;

Saunders, Lewis \& Thornhill, 2012). After several iterations, a six-stage coding scheme was arrived at: (1) experiencing through action; (2) dialoguing with self; (3) dialoguing with others; (4) abstracting from reflections; (5) changing perspectives; (6) adapting behaviors. The process whereby we arrived at this coding scheme, our findings and subsequent theorizations was consistent with the practice of iterating between theory and data as expounded by Klag and Langley (2013) and the process of 'conceptual leaping' which "generates abstract theoretical ideas from empirical data" (p. 149).

\section{FINDINGS}

We report our findings in two steps: first, we present a six-stage model of the processes of informal and incidental learning as experiened under conditions of liminality in extended independent travel; second, we offer insights into the positioning of the disorienting dilemma and the role it played in learning. We report the first of these using a combination of "power quotes" within the body of the text and further "proof quotes" compartmentalized in Table 1 (Pratt, 2008: 501). We illustrate the second (positioning disorienting dilemmas) using vignettes of individual participants. We did not quantify the analysis since, as Pratt $(2008,2009)$ cautioned, doing so in a small-sample qualitative study may lead to quantitative mind-set, misrepresentation of participants' voice, loss of meanings, or inadequate representation of the richness of the data.

\section{THE LEARNING PROCESS}

Our overall six-stage 'data structure' (see Gioia, Corley \& Hamilton, 2012) and relevant proof quotes for each of the six stages are shown in Table 1.

\section{[INSERT TABLE 1 ABOUT HERE]}

\section{Stage 1: Experiencing through action}

Participants recounted experiences to us which were wide ranging and distinctive, for example, sightseeing, training, working, volunteering, etc. They considered these experiences to be "individual and unique", either because of the people they met or that they 
did "something special", and represented a distinctive type of experience:

"You remember it, think about it, reflect on it and you tell other people the story... because it sticks with you and stays in your consciousness it may make it more of an active kind of process that keeps influencing me." (Ethan; 26)

Whilst the planned experience of the trip represented the initial stage in the learning process, participants' previous experiences also informed their learning, for example they reflected on their life at home as shaping and framing their attitudes, values and perceptions:

"I was in a really weird situation after I left Uni, I was really upset and I just thought I wish I had a different outlook on life... I was a bit more close-minded [then], like wouldn't talk to certain people because they were just different and I wasn't used to that and I would just keep away.” (Felicity; 21)

Experiences occurred unintentionally and inadvertently during the trip (for example, new unplanned activities, new friendships from chance encounters, etc.), sometimes they were seen as 'negative' (for example contemplating their options after breakdowns with their travel partners), and could lead to disorientations and unintended consequences afterwards (for example, influencing subsequent choices of educational program or career options post-trip, as well as re-evaluating personal relationships and situations for one's own safety):

"One very big event was the bombs [in India]... I was there!... It could have been me sitting there and boom, boom, boom!!! So it was quite shocking, I was quite scared... it's close to you, [so] you take it more personally... [It was] something so horrifying and lasted very long for three, four days... and the aftershocks, you feel that ok it can happen again, that was my fear!" (Vivienne; 28)

The experience of being away from home and overseas for an extended period also gave participants new knowledge and skills, for example how to live independently, taking care of oneself and others, dealing with surprises and setbacks, learning requisite people skills, etc. As a result participants reported feeling more capable, competent and self-confident.

\section{Stage 2: Dialoguing with self}

Introspection through internal dialogue (dialoguing with self) was associated with a range of feelings and emotions, as in the following examples of a participant's negative feelings of guilt in coming from a well-off family (first quote), and the importance of emotions (second 
quote):

"They [local people] had to put up with more crap, I hadn't [gone] through anything like that at all before; I just felt a bit guilty." (Gavin; 20)

"I think I probably went through every emotion I can think of at some point." (Giovanni; 19)

Reflecting was "an important big part of travelling"; for some participants it occurred as a result of having "a lot of time to think", this added value to the experience as "a year to reflect ... without anyone influencing [me]" which gave an opportunity for freedom and the power associated with being detached:

"Some time to be at peace... [because] your friends and family are the biggest influence on you." (Naomi; 23)

"Having space from all of the other things that distract you... so you are just free to reflect" (Nicole; 29)

Reflections typically focused inwardly on themselves and their past as a way to evaluate their lives and experiences, their relationships with people at home as well as with people they met on their travels. Reflection helped in making sense of how they had changed along the way (including emotions such as blame, cf. Mezirow, 1991), what is important to them, what they want out of life, how to plan for the future, and what they might do next:

"You did think about it but before ... [but] now after the [trip] I am really reflecting on this... [Even] right now I am still trying to make sense of my past learning experiences, and sometimes I blame myself for things that happened.” (Melissa; 27)

Self-reflection was the beginning of a process of abstraction (for example as a result of questioning and challenging assumptions) in which paradoxes and contradictions were scrutinized (see also Stage 4). Reflection was also inter-personal as well as intra-personal as captured in Stage 3.

\section{Stage 3: Dialoguing with others}

The context afforded participants opportunities to meet other people of different social and cultural backgrounds and with experiences similar and dissimilar to their own, and the 
opportunity to share experiences was a source of learning:

"If you weren't open and didn't speak to people, you wouldn't get anything out of the trip. Especially when you go to hostels you have to meet people, interact with people and go out with them, have a laugh, go to different sights and do things with them." (Kieffer; 30)

"...people who have come from all different walks of life and you talk to them and find out about their lives [...] it's about learning about other people's perspective as you are not the only person that matters in the world and also you learn about their lives because everyone has a fantastic story to tell." (Gabriel; 20)

Dialogue with others enabled the sharing of experiences with others (first quote) and evoked self-reflection (second quote):

"I am the first member of my family that has ever been to university, so it is a bit of a new realm. We didn't really understand it... It was a job to make a decision... A lot of people that I met there had just come out of university so you can talk to them about [it].” (Perry; 19)

"You have a lot of conversations with a lot of different people and you listen to the way their lives have developed and their perspectives and their opinions and then you have the space to reflect on that and to think about your own situation. There are a lot of times in beautiful quiet, remote locations where you are just sitting and contemplating." (Nicole; 29)

Sharing offered an outlet for frustrations, for example regarding dissatisfaction with work, disappointments in relationships, being lonely in a disorienting culture:

"It would change the way you viewed it because you could bounce of each other and play around with those emotions and turn them into funny things." (Charlotte; 20)

"[It is a] sort of emotional release, maybe it is nothing at all, but you have something that is getting you down and you need to talk to someone at the time." (McKenzie; 20)

"You are in the same place at the same time, and you get on so let's be friends... It makes you feel less lonely; you can talk to them about your family you can talk to them about anything." (Daisy; 21)

Dialogue afforded a support mechanism and a source of affirmation for participants who were unsettled by dissonant situations and disoriented by their experiences.

\section{Stage 4: Abstracting from reflections}

Abstracting in order to make sense of experiences, emotions and reflections, although often 
challenging, represented a significant forward-step in learning. Without critically evaluating

their experiences and challenging themselves, participants were unable to continue to develop beyond experiencing and dialoguing into personal change and adaptation, as in the following example:

"[It] broadens your horizons, I guess. [It] opens your mind up to different ideas and different things... I suppose you realize that when you interact with people from different countries and different cultures, when you are experiencing it firsthand...it makes you see different things." (Connor; 19)

A consistent and strong finding was that abstraction was a pivot point- - the crucial juncture in participants' learning. As well as being effortful and challenging, participants also commented that abstracting from their experiences took time but the outcome was deemed to be meaningful, as in the following example:

"I have become more philosophical now; I think about situations more and start looking at things in different ways." (Yves; 29)

One outcome was that taken-for-granted assumptions, attitudes, beliefs, and values were reevaluated:

"[The experience] really makes you evaluate yourself through what is happening and with the people you're communicating with, it has made me realize some of the challenges." (Melissa; 27)

"I was intending to see how livable [Australia] was and that is why I did spend some time living and having a job rather than acting like a tourist because I did want to see what it would be like day to day." (Gabriel; 20)

Abstraction supported participants in exploring work/life options so as to be able to plan; the process could be "eye-opening" and even disturbing, but also revealing of new opportunities and different 'horizons'.

\section{Stage 5: Changing perspectives}

In transitioning from 'abstracting' (Stage 4) to 'changing' (Stage 5) participants moved from an abstractive and interpretive phase towards a change in perspective on important issues, for example with respect to mortality (first quote) and survival (second quote): 
"[After the bombing incident] That was the [first] time I started thinking it's a big thing! It made me think about life more philosophically, something you just say I'll see you tomorrow and tomorrow never comes. I am more cautious [now]... It really affected me there, and I was feeling really uncomfortable, at that time we had stopped going out." (Vivienne; 28)

"In Africa, it rarely rains, but there are people who can't afford to eat... you come to towns with no sanitation, no running water and no electric obviously... Kenyan women walk in balancing things on their head, most people can't afford cars... they light a candle [at night] and stand by the side of the road, people trying to make a living, shining shoes, or anything... all the small things that you never see that gives you a better understanding... Well, you see people walking around here [in U.K] complaining: "It's raining again!" or "I can't believe the price of petrol has gone up!" and yet they can still afford to buy an umbrella, the petrol or a car... People [in the UK] don't appreciate what they have got. It annoys me that they are so much better off than the people in Africa but they complain three times more... So if it [the experience] affects you enough, you will remember that in Africa it could be worse." (Brayden; 24).

They were also able to make sense of the behavioral consequences of their learning:

"I had the chance to apply from I have learnt... It is important as how I will make use of all this past experience in a new kind of context. It is a lot about how you are applying them, but unless you are in that kind of situation you are not so aware of these things." (Melissa; 27)

"You've learnt but in a different situation, you take elements of certain things with you and apply it somewhere else, for instance at work." (Verity; 29)

Learning also gave participants the feeling that the options available to them had increased.

"I have always dreamed about moving from England... if it's going really well out there I will stay out there. Maybe I could have a company in both parts of the world. If it doesn't go well then I can always move back here. I think what it [gap year travel] did, it just confirmed that Australia is the place to be." (Gabriel; 20)

Participants not only gained new knowledge and skills but also were able to try out new roles, visualize new situations and circumstances, and build self-confidence.

\section{Stage 6: Adapting behaviors}

In the final stage participants transitioned from changing perspectives (for example, feeling their way into a new role or reshaped identity) to a consolidation of their transformation through adapting the way they behaved. Learnings became more integrated into day-to-day living, for example on returning home with a new realization about life's real requirements:

"We had to live out of a bag for five months and didn't really need a lot of material 
goods and possessions so [this] really simplified our lives. You don't actually need a lot to be happy." (Nicole; 29)

The process however was not always straightforward, for example the world they returned to could be restrictive:

"[Upon my return, I] have the potential to do all these things but I wasn't given the chance by other people, I am still friends with all those guys and they still see me as the old person that I was before and it is quite funny because despite the fact that I am such a different person now they still laugh at me as the old Gabriel, I think they have seen the changes but they just ignore them." (Gabriel; 20)

Looking at the broader range of possibilities that were open to them impacted on how participants saw themselves; for example, being a female domestic assistant (an au pair) for a wealthy family made one participant not only aware of the immediate importance of her role as a nanny (i.e. a responsible adult) but also of the true value of relationships with friends and family over that of material wealth, this in turn impacted her understanding of her relationship with her own mother:

"I am certainly more helpful to my own mum... to understand how difficult children can be it makes you far more appreciative of people who are in authority over you" (Whitney; 21)

We now develop the model further by turning considering the role of disorientation in learning during extended independent travel.

\section{THE ROLE OF DISORIENTING EXPERIENCES}

Thus far we have described a six-stage sequence of events from 'experiencing' through to 'transforming'. Within this process, discrepant, dissonant, or disorienting experiences and dilemmas were prominent in the accounts of many of our informants. In terms of positioning, disorienting dilemmas occurred before (nine cases), during (six cases), and after (three cases) the extended independent travel. Some participants (nine cases) did not selfreport any disorienting dilemma, whilst two participants experienced both pre- and post-trip disorienting dilemmas.

Disorientation was actually a motivation for extended independent travel for some 
participants. Dissonant social and cultural experiences encountered during the trip were also sources of disorientation, whilst for others the dissonance and disorientation surfaced after the trip. As in these examples where on returning home participants came to a realization of their new frames of references and perspectives and different lifestyle choices consequently:

"I am doing something that is more aligned to my values around trying to be a positive impact." (Ethan; 26)

"None of us had a very good job that was fulfilling, so we thought that once we had been travelling perhaps we would get a different mindset and want to do something different once we got back." (Kiefer; 30)

In further exploring the relationship between disorienting dilemma and learning we offer the following vignettes which illustrate three different ways in which the disorienting dilemma manifested in extended independent travel namely: before, during, and after the trip as illustrated in Verity's (29), McKenzie's (20) and Dylan's (23) experiences respectively.

\section{Pre-Trip Disorienting Dilemma: "I wasn't really happy at work", Verity (29)}

Verity was not happy with her job; it made her feel impatient and restless much of the time.

She felt lost and needed to find her direction in life, and therefore decided to take a half-year off to travel in Asia, Australia and the US. Verity enjoyed her travels, but it was her pre-trip experience at home which was the most important factor in her gap year travel learning, she consciously undertook the gap year in order to make sense of and resolve problems she was experiencing in her life (Experiencing through action - Stage 1):

"I wasn't really happy at work, I didn't really know what I was going to do and which direction to go into and I thought: "Oh I am going to immerse myself into somewhere totally different, not to knowing anybody and see how that turns out"..."

In self-reflecting (dialoguing with self - Stage 2), she explored her emotions and thoughts about her work situation by comparing them with how she thought and felt on the trip:

“...because I knew what it was like to be happy and I didn't want to settle for anything less than being happy. While I was travelling I realized: Yes, life is full of simple things really that can make you happy... It was probably to find out more about myself and see who I really am... that big priority about living to work and working to live." 
When Verity met people during her trip with similar experiences she was able to share her

interpretation of her situation with them (dialoguing with others - Stage 3):

"As soon as you open your mouth and start talking about something, straight away the others go: "Yes, I know what you mean", because everyone is in the same boat ... I met people who were on a career break, backpackers but everyone was like, we are going through the same things ... [They said:] "We understand what you are going through", so you didn't have to express it as much..."

This gave her a starting point for evaluating her situation and assessing what was important to her; as a result, she asked herself a number of important questions (Abstracting from reflections - Stage 4):

"I felt loyal to [them] until I started thinking while I was travelling: "Oh, they didn't treat me nice then. They weren't loyal to me so why should it go the other way around?" and that is where it sparked off.... It was more evaluating my own life: "What's important to me?", "What's not important to me?" and thinking: "What will I do?"

When Verity returned home from her travels she had more confidence, increased focus and greater decisiveness which helped her to plan personal and professional change (changing perspectives - Stage 5):

"I have been able to transfer that now to my life and especially to my workplace... When I came back I thought: "No, I am going to find another job that I know I am going to enjoy"... I am thinking of going back and doing some sort of evening education, diploma, certificate, [or] degree, whatever it may be and to be more focused about it... I did it at the right time in order to make the change... I thought: "Yep, make or break!"... I think that I am [a] proof... at the beginning it was hard because I was alone, but... it was a good test for me to start afresh."

Once she returned home Verity found a new job, moved to another city, rejuvenated her social life, arrived at a more balanced perspective; she came to feel that she had found some inner balance and harmony (adapting behaviors - Stage 6):

"My life is [now] good, I am earning far better money but more than anything my job is far more constructive, I can be creative I have people around me that support me, my friends are good to me, I am good to them... Well the shift from going from living to work as opposed working to live... So, I am pretty happy how it has worked out, really."

Verity's learning helped to resolve her pre-trip disorientation. 


\section{During Trip Disorienting Dilemma: "The travel plan that evaporated", McKenzie (20)}

McKenzie described himself as being a shy person before the trip. He wanted to travel

before he started university and so decided to travel to Central and South America with a

female acquaintance. However, a few weeks into the trip, his travel companion decided to

travel instead with another friend and left him behind. The experience caused him great

disappointment (experiencing through action - Stage 1) almost to the point of depression:

"We argued a fair bit and it was more the way we split paths like in she decided to go off on her own way because a mutual friend of ours flew out to travel with us... and they decided to go travelling without me. At the time it was very difficult for me to hear, so I was not really sure about travelling by myself or to understand how they can make that decision...For that period of time I was very depressed for about a week and contemplating perhaps flying home as well with the remainder of my money....I stayed in bed at the hostel and just kind of spent two weeks fully recovering."

During his reflections in a process of rebalancing (dialoguing with self - Stage 2) he

experienced a dilemma of whether to keep travelling or return home, this was with

accompanied by feelings of anger and mistrust:

"I just felt that she was being a little bit selfish about the trip and didn't feel that there was much compromise either... A lot of it was the organization of the trip because I did most of it with my dad, and I asked her plenty of times to help and to make input. I don't feel like she appreciated the work he [my father] put in for it which wasn't even for me a family member and so that made me more inclined to be angry about it."

Luckily for McKenzie, he was able to share his disorientation with friends at home, with new people he met during the trip, and with his best friend who flew over to visit him (dialoguing

with others - Stage 3):

"I spoke to a few friends from home [then] Alex appeared at the airport and I went to pick him up and he stayed with me for just over two weeks... He is a very, very close friend of mine, he was like: "This is your trip I trust everything you want to do" $\mathrm{He}$ pretty much put his faith in me... It helped me last until the end of the trip."

As a result, McKenzie re-evaluated his attitude to relationships and his loyalties (abstracting from reflections- Stage 4):

"I am less trusting in people like immediately, maybe that is just a consequence of what happened... It is kind of in a way almost a result of trying to protect myself from going through the experience again... If people asked me to do something for them I would just generally say yes, even if I didn't feel like necessarily wanted to do that I would do 
it to make them happy. But now, I would be less inclined to do that, not necessarily because I don't want to make them happy but because it might not come back the way I want it to."

The ability to express himself and to share his emotions helped McKenzie to get back on track with his trip. While he was originally hesitant about whether he could manage to travel by himself, his confidence and positive emotions grew as he pushed himself to continue.

McKenzie came to the conclusion that he did not need other people in order for the trip to be a success; being on his own was a new and viable perspective (changing perspectives - Stage 5), it meant that he did not have to give up, and could continue his trip successfully:

"I realized that it would be a lot easier by myself; I would not have the responsibilities that I had, I felt very happy... At first it was hard to deal with but afterwards it gave me a lot more freedom and made it more enjoyable for me to actually see things and do things and to meet new people... it is much easier being responsible for your own person...I decided that I had come this far, I was already half way through the trip, I still had a lot of things to see."

While he was able to adapt his behaviors to the situation, his transformation became even more evident after his gap year: he discovered that he had the capability to be independent and developed the people skills that he previously lacked.

"It has had a lasting effect on my attitude towards travelling... I am a more confident person travelling by myself... I am much more comfortable about spending time away from my parents or my friends now... and am capable of living by myself, which I think was [a] good preparation for university. I didn't realize at first how easy it is."

He subsequently travelled solo in Europe (adapting behaviors - Stage 6) and led a fulfilling social life during his first year of university.

\section{Post-Trip Disorienting Dilemma: "People changed me", Dylan (23)}

Dylan came from a family who enjoyed travelling and he had travelled extensively. The trip he chose to discuss was his second gap year and his first extended round-the-world trip alone; in it he travelled to South and Central America, Australasia, South and South-East Asia.

Dylan's passion for people, their lives and culture were apparent, he was positively disposed to understanding different ways of life and other lifestyle options, it was part of his identity (experiencing through action - Stage 1): 
"Every moment of your [travelling] day is interesting, your whole day is just full of fun and you just feel really happy with life... you get to understand more about the world and different cultures... by meeting people you learn more about the place and certain things."

On this trip at this point in his life experiencing different cultures prompted him to reflect on his personal values and career options, as a result he reflected on various alternatives which arose during the course of his trip (dialoguing with self - Stage 2):

"[Travelling time] is quite a reflective time when you just think about lots of different things. I have got an inquisitive mind. I went travelling just to see what else is out there. The more you are exposed to different cultures and different ideas, the more you can decide what you think about things, to pick and choose to a certain extent things what you like about how they live and then try and bring that into your life"

Time off during the gap year afforded him space to "think things over in your head and analyze how you are feeling." Dylan talked a lot to people he met along the way, and he came to realize that there were lifestyle choices available to him that involved different sets of values (for example, non-financial) (dialoguing with others - Stage 3):

“...my mate who I was travelling with was massively 'anti' [against] graduate training schemes, and so I think some of his ideas have rubbed off on me and probably some of mine on him as well... my feelings were changed by people around me, seeing what their ambitions are and how they can continue to travel through their job; I met a lot of people who were working but still travelling through their job... you don't need to have a lot of money to enjoy yourself and I saw this from lots of people that I met travelling"

These reflections impacted on how he thought about his lifestyle choices and career options; he re-appraised his educational and career assumption that he would study to become a lawyer, which is a highly paid profession, and therefore be able to finance a certain 'lifestyle') (abstracting from reflections - Stage 4):

"Before I went travelling, I definitely was $100 \%$ certain that I wanted to do a law conversion course and do that for two years and become a solicitor. I am still quite keen on that idea, but I think maybe less into the lifestyle that being a solicitor in a big law firm. I [now] can imagine [that] working in any special law firm you would have to be quite cutthroat and quite sort of hard on people to get to a high position and I am not entirely sure, and also the work would be very intense. I am [now] more open to a job that I could enjoy more and one that I would have more free time."

Upon his return home, he delayed his decision to pursue his legal studies and considered an 
alternative path (changing perspectives - Stage 5):

"But since I have been travelling I have been thinking a lot, I want to find a balance between a job and my leisure activity because I don't want to live to work, I don't want a job that is going to take over my whole life or to be driven massively in my job, I don't want the most important thing in my life to be my work I want it to be my friends, family and my happiness. So now I want to go into something slightly different, maybe still in law but I don't want to work for a big corporate law firm, I don't want to tread on peoples fingers to get to where I want to be. Maybe going into teaching..."

Dylan experienced a post-trip disorienting dilemma in which his identity as someone who would follow a well-trodden path into the legal profession which would enable him to finance a certain life style was called in to question. As a result, his career choice was put very much on hold (adapting behaviors - Stage 6):

"One of the things that will drive me to get a job that is well paid [is]... when I want to have a family. Otherwise I would be quite happy to travel and work, travel and work for a few more years... I was thinking about next year, learning Italian in the ski season in Italy, so I would learn Italian, Spanish and French and then after that try and find a career."

In Dylan's case, the disorienting dilemma occurred after the trip; the trip was a catalyst for change in his values (his meaning frames in transformative learning terms) and had identity effects, at the time of the interview the story was unfinished: he needed more time to work out what his next steps might be. Dylan was disoriented by an uncomfortable sense of self, his learnings which collided with some things 'taken-for-granted' helped to move him forward to a less uncomfortable and ultimately more comfortable self of self. The liminality he and the other participants experienced in being divorced from existing structures and known ways of 'doing and being' contributed to a sense of uncertainty over identity and their sense of self (Simpson et al, 2009: 55). In the case of Dylan and other participants a process of learning enacted in the liminal space of extended independent travel enabled a 're-authored self' to emerge (Land et al., 2005), liberated from habitual meaning frames and with a sense of autonomy and personal freedom.

\section{DISCUSSION}

Learning is not the explicit purpose of extended independent (gap year) travel, but as our 
research has shown significant, and sometimes transformational, learnings do occur. How can this be so? What are the processes that are at work in extended independent travel that result in informal and incidental learnings that seem to be so powerful and transformative? How can these be theorized and what lessons can be learned for the informal and formal development programs that we put into place for young people and early career professionals in higher education in general and in management learning and education in particular? To this end we frame our findings in terms of a six-stage model of how learning occurs informally and incidentally in the liminal space of extended independent travel (see Figure 1). In doing so, we contribute to the informal and incidental learning, liminality, and management learning and education and wider literatures in several ways.

\section{[FIGURE 1 HERE]}

Our first contribution is in relation to the theories of informal and incidental learning in a novel setting (extended independent travel) conceptualized as a 'liminal space'. Prior research has focused on informal and incidental learning in educational and workplace contexts (Boud \& Middleton, 2003; Eraut, 2004; Marsick \& Watkins, 1990; Marsick et al., 2017) however it seems to us that liminal spaces such as that instantiated in extended independent (gap year) travel are a fertile arena for understanding informal and incidental learning for a number of reasons: first, learning is not the main objective (i.e. formalized or intentional) of the gap year; second, gap year invariably entails an inter-cultural dimension whereby young people venture outside of their familiar zone of experience and enter into a liminal space which creates opportunities for ‘jolts' (Marsick \& Volpe, 1999) or disorienting dilemmas (Mezirow, 1991) which catalyze learning.

Second, in analyzing our data we drew on and synthesized pertinent concepts from relevant theories, namely informal and incidental learning theory (Marsick \& Watkins, 1990), Kolb's experiential learning theory, Mezirow's transformative learning theory, and liminality 
(Turner, 1974). We constructed a model which is not the familiar cycle (cf. Kolb) but rather-in line with conceptions of liminality and transformation - a progression whereby the learner's "older prevailing view" transitions to an "alternative version of this self" via a "letting go of the learner's earlier mode of subjectivity", (Land et al., 2014: 201) with exchanges taking pace at various critical points in a progressive process. The first of these is between 'dialogue with self' to 'dialogue with others' and back, we label this a 'reflective' phase, involving making sense of our actions via reflective "dialogue with self or others" (Cunliffe, 2002: 43). The second is between changing perspectives to adapting behaviors, we labelled this a 'reflexive' phase, involving the ability to problematize assumptions and generate different perspectives (Cunliffe, 2002). A transformative outcome of reflexivity is a complexity of thinking that exposes contradictions, doubts, and dilemmas but which also entertains new possibilities (Chia, 1996). The model is a sequence from an initial state (old 'habituated' ways of being') to a closing, though by no means finished, state (new 'reauthored' ways of being) with the positioning of the disorienting dilemma's catalyzing role at various points. There is a progression from a prior 'habitual' way of being to 're-authoring', whereby a new internal model is constructed which is a "guide to identity and action" on the basis of a "replacement narrative" of the self (Tennant, 2000: 93). The process is presented as cyclical to the extent that the 're-authored self' may (Land et al., 2014; Tennant, 2000), as circumstances change and new liminalities are experienced, become ossified into a 'habituated self' (hence the feedback arrow in Figure 1).

Third, our research sheds light on the relationship between experience and meaningmaking in the context of extended independent (gap year) travel. Transformative learning is defined as "new or revised interpretation of the meaning of one's experience", (Mezirow, 1996: 163, emphasis added), however a criticism of transformative learning theory is that what constitutes an 'experience' is often not well-defined (Taylor \& Cranton, 2013: 35-37). In order to move forward, Taylor and Cranton highlighted the need for transformative 
Learning in the liminal space of extended independent travel

learning research to acknowledge the significance of culture or personal history (i.e.

biography) and examine the role of discrepant experiences in contradicting culturally and biographically embedded assumptions and values. Our research addresses this shortcoming by grounding itself in a unique and well-defined context (extended independent travel) in which clearly delineated experiences_-sometimes dissonant, discrepant or disorienting, are encountered in often times strange and unfamiliar settings which contradict past experiences and lead to reflection, interpretation and transformation via informal and incidental learning processes. The transformations that were evident in our data occurred at a critical life juncture (in our case the 'gap year'), this sense they were 'one-offs' at a particular point in time (most people transition from higher education to work or high school to higher education once only, and most 'gappers' only take one 'gap year'). Hence, the model of learning we present is not a cycle whereby a new round of transformation begins once the process is complete; rather it is has a beginning and an end in the particular liminal space (gap year travel) that was the focus of our study (although we make further observations on this issue since any individual life trajectory is likely to entail various liminalities, e.g. from full-time career to retirement).

Fourth, a notable feature of the liminal aspect is the frequent reference researchers make to it as a 'transformative state', as having a 'transformative function', and of shifts that take place within the liminal space (see Land et al., 2013; Meyer \& Land, 2006). A problematic aspect of this discourse is the tenuous link in liminality research (e.g., Land et al., 2014) to transformative learning as widely understood and expounded by its originator, Mezirow (see Schwartzman, 2010). In our research, and thereby addressing this shortcoming in prior work, we make clear theoretical links from transformative learning theory to the liminality literature. We do so via the concept of meaning as arising out of the experience of liminality (in the context of extended independent travel) and in relation to the assumptions and habitual sets of expectations within which past experiences are assimilated 
(Schwartzman, 2010). It seems to us that the changes that participants reported in their meaning frames could be interpreted in terms of them not simply being subject to on-going and continual refinement as would be the case in ordinary encounters with the world (Schwartzman, 2010) but instead being subject to more radical undoing and re-authoring (Land et al., 2014; Tennant, 2000) as a result of an encounter with, and as a response to, things which are unfamiliar and confusing, see above. Our research affords examples of the role of dissonant, discrepant and disorienting experiences in relation to informal and incidental learnings in the pre-liminal, liminal and post-liminal spaces; it is to this latter point which we now turn.

Fifth, our research contributes to debates and critiques within transformative learning scholarship regarding the status and positioning of the disorienting dilemma. In classic expositions of the theory the disorienting dilemma is placed as the first element or phase in the process (Mezirow \& Marsick, 1978; Mezirow, 1991). Transformative learning scholars who are critical of Mezirow's theory have argued recently that the process may begin more gradual: "transformative learning may begin unnoticed, incidentally, and sometimes casually" (Nohl, 2013: 45). Nohl and others call into question the primacy of the disorienting dilemma as the only way by which the transformative learning process can begin. We discovered that dissonance, discrepancy or disorientation may occur before, during or after an episode of extended independent travel (the liminal space). This resonates with the concepts of preliminality, liminality, and post-liminality as expounded by cultural anthropologists as foundational aspects of liminality theory (van Gennep, 1909; Turner, 1974). Hence in our model the dissonant, discrepant and disorienting experiences or dilemmas can be positioned in the pre-liminal space, liminal space, or post-liminal space (this is consistent with the anthropological view). In the post liminal space it is the re-authored self (see Land et al., 2014) can be the source of dissonance and disorientation. We summarize these various concepts and relationships in Figure 1 above. 
Finally, our research presents a contribution to the study of learning and travel (a "neglected tourism research area", Falk et al., 2012: 908) and an opportunity for cross fertilization between tourism studies and management learning and education. Extended independent (gap year) travel learning is distinctive in that it emplaces learners who are in transition into novel social-cultural circumstances in which dissonance may be encountered and bring about a 'jolt' (Marsick \& Volpe, 1999) or 'disorientation' (Mezirow, 1990). Travel in general is a space which is replete with opportunities for informal and incidental learnings (Falk et al., 2012); extended independent travel in particular is a context in which transformative learning may take place and hence represents a special, and most interesting, case of travel and learning. Various factors, many of them novel attributes of the context, catalyze learning in the unique 'learning laboratory' of travel.

\section{PEDAGOGICAL AND PRACTICAL IMPLICATIONS}

The processes and outcomes we have observed are unlikely to be confined to extended independent travel since this is but one example of a 'rite of passage'. Learning experiences where old structures and meanings no longer apply and earlier selfhoods become stripped away (Simpson et al., 2009) are likely to be common to students not just those taking a gap year. Indeed, it may be the case that the issues we have studied here in the context in which we have studied them (e.g., informal and incidental learning, liminality) have been overlooked in the higher education literature more generally since transitions between different types of education necessarily implicate informal and incidental learning in liminal spaces, hence its wider implications could be profound and far-reaching.

Turning to the specifics of business education, taught post graduate programs in business schools often have a high proportion of non-domestic students (as in students from eastern cultures coming west and vice versa). In encountering different cultures for the first time we would be surprised if such students did not experience disorienting dilemmas during their studies, indeed our own pedagogical experiences and pastoral responsibilities indicate 
this is often the case. Hence, our model has both pedagogical and pastoral implications for business schools and how they induct and care for their students, especially in the early stages of programs for both foreign and home students. Many students undertake work placements as part of their studies both at home and abroad and are likely to experience similar liminality effects, as are expatriates in the workplace. The disorientation brought about by interpersonal and intercultural, social and cultural dissonance, discrepancy and disorientation can be a positive opportunity for significant learning in which transformation — under the right and correctly managed circumstances — might take place. We would be surprised if our model did not extend beyond 'gappers' to intercultural learning and educational transitions more generally. The relevance also extends to self-direction in learning given that the latter involves an awareness of change, processes of change and intentionality (Boyatzis et al., 2002) and that self-awareness was central to the processes and outcomes we have observed.

The findings of our research will be of relevance to gappers, their family members and friends in planning their overseas experiences. Reflections that are catalyzed as a result of travel in novel socio-cultural settings at crucial life junctures amplify the potential for transformation. Creating the space for reflections and interpretation may help to maximize learning from what will be for many a very expensive and once-in-a-lifetime experience. Similarly, understanding the processes and outcomes of extended independent travel will also be of likely benefit to friends and family post-trip in order that they may be alerted to the transformations that may occur during, or after (for example by the trip evoking a disorienting dilemma) the trip and hence be ready for and prepared to manage these situations. Given the expansion in business school education in recent years the question arises of whether these implications also apply to foreign (e.g. Asian) students emplaced in the socio-culturally-specific learning settings of North American, European, or Australian business schools, and whether these processes impact on their learning experience. 
Learning in the liminal space of extended independent travel

travel may assist educational institutions in anticipating and understanding the experiences of students who have taken, or are contemplating (either during or after college), such a trip.

High school institutions, for example, could prepare students who plan to embark on extended independent travel on graduating by alerting them to processes of interpretation and transformation and by encouraging reflexivity. Business schools, and colleges and universities in general, could anticipate both the needs and potential learning challenges of educating gap year students by better understanding the lived experiences of students who have undertaken extended independent travel. Moreover, the learnings of such students may offer a useful resource to others within educational establishments. Their experiences also are likely to prove to be a valuable resource in formal learnings at college or university and in work, for example in learning about workplace behaviors in different cultures, decision making and vocational choice. These pedagogical implications are likely to extend to study abroad and other forms of intercultural learning. Finally, those travel companies who offer extended independent travel (such as gap year) services to young people might be able to utilize our findings to develop a more evidenced-based range of products and services, for example packages which support and maximize learnings before, during and after the trip.

\section{LIMITATIONS, FUTURE RESEARCH AND CONCLUSION}

Our research is based on retrospective verbal accounts elicited via a series of in-depth interviews. The limitations associated with such approaches are well-documented (Miller, Cardinal, \& Glick, 1997) and continue to be debated (Bryman, 2013). Yet, the criteria for evaluating qualitative research are different than those for quantitative research. From the subjectivist and interpretivist stance we adopted (Morgan \& Smircich, 1980; Smith et al., 2009), the close relationship between researcher and participants is to be valued. The focus on generating theoretical or logical generalizations rather than statistical generalizations should be appreciated, and an understanding of the lived experiences of a small number of carefully selected individuals (rather than a large sample size to represent a wider population) 
Learning in the liminal space of extended independent travel acknowledged (Giorgio \& Giorgio, 2008). The insights, meanings and disclosure of subjective experiences may only be accomplished through mutual participation and active engagement, thus subjectivity should be acknowledged for its merits. In terms of reliability, our participants' stories were a source of information which generated rich data and, for us, fascinating narratives. Our study addressed many of these concerns through multiple interviews, theoretical saturation, member-checking, audit trails, ethical considerations, and not least by the reflexivity we as researchers sought to practise (Hibbert, Sillince, Diefenbach, $\&$ Cunliffe, 2014). Although we present a model of the learning process, we are aware that this is not 'processual' in the sense that a process organization scholars may consider it (Langley et al., 2013), that said because transition and transformation are concerned with temporality there is likely scope for processual studies rooted in an ontology of becoming. Future research might study the relationships between different types of trips and learning processes and learning outcomes; the model could be tested in other contexts such as the experiences of foreign students on undergraduate and post-graduate business programs as well as in study abroad and international student exchange programs. Alternative research designs using large samples and other data collection methods (e.g. large-scale cross sectional surveys) could be used to test hypotheses developed from our model and to study different types of experiences, level of experience with overseas travel, and the effects of learning styles on the process and its outcomes. Finally, and most importantly, time horizons could be extended in order to study the longer-term effects of learning under conditions of liminality at various points in the life course and assess its impact on the on-going construction and reconstruction of the self in adjusting to an ever-emergent social environment. As the great American pragmatist philosopher George Herbert Mead (1934: 215) noted, in 'adjusting to the emergent' each one of us "becomes a different individual". 


\section{REFERENCES}

American Psychological Association. 2002. Ethical principles of psychologists and code of conduct. Washington, D.C.: American Psychological Association.

Armstrong, S. J., \& Fukami, C. V. (Eds.). 2009. The SAGE handbook of management learning, education and development. London: SAGE.

Bhawuk, D., \& Brislin, R. 2000. Cross-cultural training: a review. Applied Psychology: An International Review, 49(1): 162-191.

Borg, E., \& Söderlund, J. 2014. Liminality competence: An interpretative study of mobile project workers' conception of liminality at work. Management Learning, 46(3): 260-279.

Boud, D., \& Middleton, H. 2003. Learning from others at work: communities of practice and informal learning. Journal of Workplace Learning, 15(5): 194-202.

Boyatzis, R. E., Stubbs, E. C., \& Taylor, S. N. 2002. Learning cognitive and emotional intelligence competencies through graduate management education. Academy of Management Learning \& Education, 1(2): 150-162.

Bryman, A. 2004. Social research methods. New York: Oxford University Press.

Bryman, A. 2013. Doing research in organizations. Abingdon: Routledge.

Che, M., Spearman, M., \& Manizade, A. 2009. Constructive disequilibrium. In R. Lewin (Ed.) The handbook of practice and research in study abroad: Higher education and the quest for global citizenship: 99-116. New York: Routledge.

Chia, R. 1996. The problem of reflexivity in organizational research: Towards a postmodern science of organization. Organization, 3(1): 31-59.

Chin, M.M., \& Kuo, S.W. 2009. From Metacognition to Social Metacognition: Similarities, Differences and Learning. Journal of Education Research, 3(4): 321-338.

Crabtree, B. F., \& Miller, W. L. 1999. Doing qualitative research. Thousand Oaks, CA: SAGE.

Cranton, P. 1994. Understanding and promoting transformative learning: A guide for 
educators of adults. San Francisco: Jossey-Bass.

Crawford, C. \& Cribb, J. 2010. Gap year takers: Uptake, trends and long term outcomes. Research Report: DFE-RR252. London: Institute for Fiscal Studies for Department of Education.

Cunliffe, A. L. 2002. Reflexive dialogical practice in management learning. Management Learning, 33(1): 35-61.

Dirkx, J. M. (2012). Self-formation and transformative learning. Adult Education Quarterly, 62(4): 399-405.

Duncan, T. 2004. Livin'the dream: Working and playing in a ski resort. Paper Presented at Institute of British Geographers and International Geographical Union Geography of Tourism and Leisure Working Group Pre-Meeting, Loch Lomond, Scotland.

Eraut, M. (2004). Informal learning in the workplace. Studies in Continuing Education, 26(2), 247-273.

Falk, J.H., Ballantyne, R., Packer, J., \& Benckendorff, P. 2012. Travel and learning: A neglected tourism research area. Annals of Tourism Research, 39(2): 908-927.

Field, J. (2012). Transitions in lifelong learning: public issues, private troubles, liminal identities. Studies for the Learning Society, 2(2-3), 4-11.

Gioia, D. A., Corley K.G., \& Hamilton, A. L. 2012. Seeking qualitative rigor in inductive research. Notes on the Gioia methodology, organizational research method. Organizational Research Methods, 16(1): 15-31.

Giorgio, A., \& Giorgio, B. 2008. Phenomenology. In Smith, J. A. (Ed.), Qualitative psychology: A practical guide to research methods. London: SAGE: 26-52.

Grabove, V. 1997. The many facets of transformative learning theory and practice. New Directions for Adult and Continuing Education, 74: 89-96.

Gubrium, J.F., \& Holstein, J.A. 1995. The Active Interview. Thousand Oaks: SAGE

Gubrium, J.F., \& Holstein, J.A. 1997. The new language of qualitative methods. New York: 
Oxford University Press.

Hawkins, B., \& Edwards, G. 2015. Managing the monsters of doubt: Liminality, threshold concepts and leadership learning. Management Learning, 46(1): 24-43.

Heath, S. 2007. Widening the gap: Pre-university gap years and the 'economy of experience'. British Journal of Sociology of Education, 28(1): 89-103.

Hibbert, P., Sillince, J., Diefenbach, T., \& Cunliffe, A. L. 2014. Relationally reflexive practice a generative approach to theory development in qualitative research. Organizational Research Methods, 17(3): 278-298.

Inkson, K., \& Myers, B.A. 2003. The big OE: Self-directed travel and career development, Career Development International, 8(4): 170-181.

Johan, N. 2009. Gap Year Travel: Youth Transition or Youth Transformation? In Brooks, R. (Ed.) Transitions from education to work: New perspectives from Europe and beyond: 136-149. London: Palgrave Macmillan.

Jones, A. 2004. Review of gap year provision. Journal of Intercultural Relations, 21(4): $475-490$.

Kayes, D. C. 2002. Experiential learning and its critics: Preserving the role of experience in management learning and education. Academy of Management Learning \& Education, 1(2): $137-149$.

King, A. 2011. Minding the gap? Young people's accounts of taking a gap year as a form of identity work in higher education. Journal of Youth Studies, 14(3): 341-357.

King, N. 1998. Template Analysis, In G. Symon \& C. Cassell (Eds.), Qualitative methods and analysis in organizational research: 271-287. London: SAGE.

King, N. 2010. Research ethics in qualitative research. In M.A. Forrester (Ed.), Doing qualitative research in psychology: A practical guide. London: SAGE.

Klag, M., \& Langley, A. 2013. Approaching the conceptual leap in qualitative research. International Journal of Management Reviews, 15(2): 149-166. 
Learning in the liminal space of extended independent travel

Kolb, D. A. 1984. Experiential learning: Experience as the source of learning and

development. New Jersey: Prentice-Hall.

Kolb, D.A. 2014. Experiential learning: Experience as the source of learning and development ( $2^{\text {nd }}$ edition $)$. Upper Saddle River, N.J.: Pearson.

Kolb, A. Y., \& Kolb, D. A. (2010). Learning to play, playing to learn: A case study of a ludic learning space. Journal of Organizational Change Management, 23(1), 26-50.

Land, R., Rattray, J., \& Vivian, P. (2014). Learning in the liminal space: a semiotic approach to threshold concepts. Higher Education, 67(2): 199-217.

Langley, A. (1999). Strategies for theorizing from process data. Academy of Management Review, 24(4), 691-710.

Langley, A., \& Abdallah, C. 2011. Templates and turns in qualitative studies in strategy and management. Research Methodology in Strategy and Management, 6: 201-235.

Langley, A., Smallman, C., Tsoukas, H., \& Van de Ven, A. H. 2013. Process studies of change in organization and management: Unveiling temporality, activity, and flow. Academy of Management Journal, 56(1): 1-13.

Levinson, D., Darrow, C., Klein, E., Levinson, N., \& McKee, B. 1978. The seasons of a man's life. New York: Knopf.

Li, M., Mobley, W. H., \& Kelly, A. 2013. When do global leaders learn best to develop cultural intelligence? An investigation of the moderating role of experiential learning style. Academy of Management Learning \& Education, 12(1): 32-50.

Loker-Murphy, L., \& Pearce, P.L. 1995. Young budget travelers: Backpackers in Australia. Annals of Tourism Research, 22(4): 819-843.

Lyons, K., Hanley, J., Wearing, S., \& Neil, J. 2012. Gap year volunteer tourism: Myths of global citizenship? Annals of Tourism Research, 39(1): 361-378.

Marshall, M. N. 1996. Sampling for qualitative research. Family Practice, 13(6): 522-526. Marsick, V. J., \& Volpe, P. 1999. The nature and need for informal learning. Advances in 
Developing Human Resources, 1(3): 1-9.

Marsick, V. J., \& Watkins, K. E. 1990. Informal and incidental learning in the workplace. London: Routledge.

Marsick, V.J., \& Watkins, K.E. 2001. Informal and incidental learning. New Directions for Adult and Continuing Education, 89 (Spring): 25-34

McLaughlin, J.S., \& Johnson, D.K. 2006. Assessing the field course experiential learning model: Transforming collegiate short-term study abroad experiences into rich learning environments. Frontiers: The Interdisciplinary Journal of Study Abroad, 13: 65-85.

McWhinney, W., \& Markos, L. (2003). Transformative education across the threshold. Journal of Transformative Education, 1(1), 16-37.

Mead, G. H. 1934. Mind, self and society. University of Chicago Press: Chicago.

Meyer, J. H., \& Land, R. 2005. Threshold concepts and troublesome knowledge (2):

Epistemological considerations and a conceptual framework for teaching and learning. Higher Education, 49(3): 373-388.

Mezirow, J. 1990. Fostering critical reflection in adulthood: A guide to transformative and emancipatory learning. San Francisco: Jossey-Bass.

Mezirow, J. 1991. The transformative dimensions of adult learning. San Francisco: JosseyBass.

Mezirow, J., \& Marsick, V. 1978. Education for perspective transformation: Women's reentry programs in community colleges. New York: Center for Adult Education, Teachers College, Columbia University.

Mezirow, J. (2000). Learning to think like an adult. In Mezirow, J. (Ed.). Learning as transformation: Critical perspectives on a theory in progress. pp. 3-33. San Francisco: Jossey-Bass Publishers

Miller, C.C., Cardinal, L.B., \& Glick, W.H. 1997. Retrospective reports in organizational research: A reexamination of recent evidence. Academy of Management Journal, 40: 189- 
204.

Mintel. 2005. Gap Year Travel - International. Travel and Tourism Analyst, 12. London: Mintel International Group Ltd.

Mor, S., Morris, M.W., \& Joh, J. 2013. Identifying and training adaptive cross-cultural management skills: The crucial role of cultural metacognition. Academy of Management Learning \& Education, 12(3): 453-475.

Morgan, G., \& Smircich, L. 1980. The case for qualitative research. Academy of Management Review, 5(4): 491-500.

Mosakowski, E., Calic, G., \& Earley C. P. 2013. Cultures as learning laboratories: What makes some more effective than others? Academy of Management Learning \& Education, 12(3): 512-526.

Nahavandi, A. (2016). Threshold concepts and culture-as-meta-context. Journal of Management Education, 40(6), 794-816.

Nohl, A. M. (2015). Typical phases of transformative learning: A practice-based model. Adult Education Quarterly, 65(1): 35-49.

O’Sullivan, E., Morrell, A., \& O’Connor, M.A. 2002. Expanding the boundaries of transformative learning: Essays on theory and praxis. New York: Palgrave.

O'Reilly, C. C. 2006. From drifter to gap year tourist: Mainstreaming backpacker travel. Annals of Tourism Research, 33(4): 998-1017.

O'Shea, J. 2014. Gap year: How delaying college changes people in ways the world needs. Baltimore: Johns Hopkins University Press.

Otten, M. (2003). Intercultural learning and diversity in higher education. Journal of Studies in International Education, 7(1): 12-26.

Pless, N. M., Maak, T. \& Stahl, G. K. 2011. Developing responsible global leaders through international service-learning programs: The Ulysses experience. Academy of Management Learning \& Education, 10(2): 237-260. 
Pratt, M. 2008. Fitting oval pegs into round holes: Tensions in evaluating and publishing qualitative research in top-tier North American journals. Organizational Research Methods, 11(3): 481-509.

Pratt, M. 2009. From the editors. For the lack of a boilerplate: Tips on writing up (and reviewing) qualitative research. Academy of Management Journal, 52(5): 856-862.

Raelin, J. A. (2001). Public reflection as the basis of learning. Management Learning, 32(1), 11-30.

Reynolds, M., \& Vince, R. 2007. Handbook of experiential learning and management education. Oxford: Oxford University Press.

Robson, C. 2002. Real world research. Oxford: Blackwell Publishing.

Saldana, J. 2009. The coding manual for qualitative researchers. London: SAGE.

Saunders, M., Lewis, P., \& Thornhill, A. 2012. Research methods for business students. Harlow: Pearson Education Limited.

Schön, D.A. 1983. The reflective practitioner: How professionals think in action. New York: Basic Books

Schwartzman, L. (2010). Transcending disciplinary boundaries: A Proposed Theoretical Foundation for Threshold Concepts. In Meyer, J.H.F, Land, R. and Baillie, C. (2010) Threshold Concepts and Transformational Learning. Rotterdam, Boston and Taipei: Sense Publishing, pp.21-44.

Silverman, D. 1993. Interpreting qualitative data: Methods of analyzing, talk, text and interaction. London: SAGE.

Simpson, K. 2004. 'Doing development': The gap year, volunteer-tourists and a popular practice of development. Journal of International Development, 16(5): 681-692.

Simpson, K. 2005. Dropping out or signing up? The professionalization of youth travel. Antipode, 37(3): 447-469.

Simpson, R., Sturges, J., \& Weight, P. 2009. Transient, unsettling and creative space: 
Experiences of liminality through the accounts of Chinese students on a UK-based MBA.

Management Learning, 41(1): 53-70.

Smith, J., Flowers, P., \& Larkin, M. 2009. Interpretative phenomenological analysis:

Theory, method and research. Thousand Oaks: SAGE.

Snee, H. 2013. Framing the other: Cosmopolitanism and the representation of difference in overseas gap year narratives. The British Journal of Sociology, 64(1): 142-162.

Stein, S., Lauer, Y., \& El-Kharbili, M. 2009. Using template analysis as background reading technique for requirements elicitation. GI Software Engineering, 143-LNI: 127-138.

Stone, M.J., \& Petrick, J.F. 2013. The educational benefits of travel experiences: a literature review. Journal of Travel Research, 52(6): 731-744.

Strauss, A. L., \& Corbin, J. 1998. Basics of qualitative research: Techniques and procedures for developing grounded theory. Thousand Oaks, CA: SAGE.

Suddaby R. 2006. From the editors: What grounded theory is not. Academy of Management Journal, 49: 633-642.

Taylor, E. W. 1994. Intercultural competency: A transformative learning process. Adult Education Quarterly, 44(3): 154-174.

Taylor, E. W. 1997. Building upon the theoretical debate: A critical review of the empirical studies of Mezirow's transformative learning theory. Adult Education Quarterly, 48(1): 3459.

Taylor, E. W., \& Cranton, P. 2013. A theory in progress? Issues in transformative learning theory. European Journal for Research on the Education and Learning of Adults, 4(1), $35-47$.

Tempest, S., \& Starkey, K. 2004. The effects of liminality on individual and organizational learning. Organization Studies, 25(4): 507-527.

Tennant, M. (2000). Adult learning for self-development and change. In Wilson A.L. \& Hayes, E.R (Eds.) Handbook of adult and continuing education. San Francisco: Jossey 
Bass: $87-100$.

Teo, P., \& Leong, S. 2006. A postcolonial analysis of backpacking. Annals of Tourism Research, 33(1): 109-131.

Turner, V. W. 1969/1996. The ritual process: Structure and anti-structure. New Jersey: Transaction Publishing.

Turner, V. W. 1974. Betwixt and between: The liminal period in rites of passage. In L.C. Mahdi, S. Foster, \& M. Little (Eds.) Betwixt and between: Patterns of masculine and feminine initiation: 3-19. La Salle: Open Court.

Van Gennep, A. 2011. The rites of passage. Chicago: University of Chicago Press.

Yamazaki, Y., \& Kayes, D. C. 2004. An experiential approach to cross-cultural learning: A review and integration of competencies for successful expatriate adaptation. Academy of Management Learning and Education, 3(4): 362-379. 


\section{FIGURE 1.}

Six-stage model of of informal and incidental learning as experiened under conditions of liminality in extended independent travel

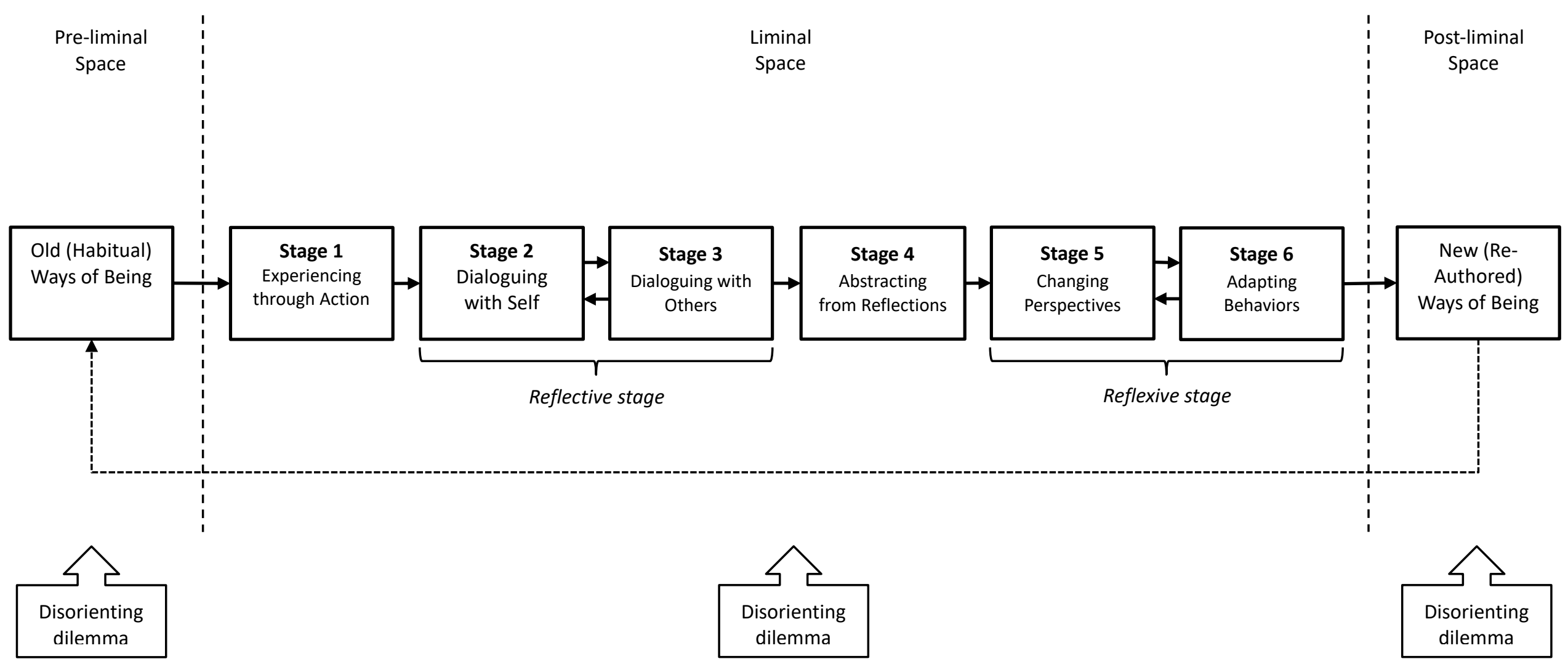


Learning in the liminal space of extended independent travel

TABLE 1.

Stages of learning under liminality (ELT and TL stages* and participant name/number in parentheses)

\begin{tabular}{|c|c|}
\hline Stage (Codes) & Illustrative quotes \\
\hline $\begin{array}{l}\text { Experiencing through } \\
\text { action (ELT1; TL1) }\end{array}$ & $\begin{array}{l}\text { "You always hear what life is like in Africa but you never know until you go... } \\
\text { Things that you never realize... It makes your picture of life in a different } \\
\text { country with a different culture more complete. That gives you a better } \\
\text { understanding." (Brayden; 24). } \\
\text { "I was charging around on my motorbike and I didn't really think of the } \\
\text { consequences and obviously... I had to sit down for quite a while, I couldn't } \\
\text { really move for three or four weeks. That was quite bad, I could have died!" } \\
\text { (Connor; 19) } \\
\text { "I remember that I opened my eyes and I was like: Where am I? I sort of pictured } \\
\text { the distance of like how far away I am from home and how different this place } \\
\text { is... it was the first time and I didn't know what to expect." (Vivienne; 28) }\end{array}$ \\
\hline $\begin{array}{l}\text { Dialoguing with self } \\
\text { (ELT2;TL2;TL4) }\end{array}$ & $\begin{array}{l}\text { "I felt that I didn't really deserve it, to be honest because I was a bit of an ****** } \\
\text { to them... And for them to come all the way to come and see me and support } \\
\text { me. It was lifting but at the same time I felt really bad about it all." (Keanu; 22) } \\
\text { "[I reflect on] the people, the experiences, and how it's sort of changed me and } \\
\text { how I acted in certain situations and whether I would have acted differently. On } \\
\text { reflection now, I would probably do things differently if I was to repeat the } \\
\text { experience." (Charlotte; 20) } \\
\text { "I was freaking out a bit. It made me feel lost to be honest... Everyone else had a } \\
\text { very sort of corporate mindset and I just wasn't feeling like that at all. I felt that } \\
\text { I was below them... I am going to have to again be like a fast pace, thinking } \\
\text { fast..." (Felicity; } 21 \text { ) } \\
\text { "I just thought I am on my own, quite far from anybody, [with] no responsibility... } \\
\text { Before I knew whatever I decided to do,... I could just unpack properly and } \\
\text { relax and think where do I really want to go, what is my priority." (Chloe; } 24) \\
\text { "I really felt out of my depth, a bit over my head it was a bit crazy. I was thinking } \\
\text { about how long I had to go there and I was wondering: "Am I going to start } \\
\text { liking it?"... Well, people were nice and stuff but it was a bit of a shock." } \\
\text { (Gavin; 20) }\end{array}$ \\
\hline $\begin{array}{l}\text { Dialoguing with others } \\
\text { (TL4) }\end{array}$ & $\begin{array}{l}\text { "[It was] talking to other people and what they have done and what they were } \\
\text { doing was quite good, [I] kind of grabbed ideas from different people" } \\
\text { (Rebecca; 26) } \\
\text { "When you meet people in general you cannot talk about our life but when I met } \\
\text { people and friends when I was travelling I could talk about our life... How can I } \\
\text { say, not really general things, it's different...." (Ella; 21) } \\
\text { "I got to know them and their past and how they think... I was quite irresponsible } \\
\text { and they told me: "You can't be like this", "You have to do this, that", "To } \\
\text { succeed in life you have to have your head screwed on!" (Felicity; 21). } \\
\text { "Vanessa knew me inside out... it's nice to have someone there that knows you so } \\
\text { you could talk to them knowing that they have experienced the same thing... } \\
\text { She knows me so well that she could tell when I was upset and when I was } \\
\text { homesick." (Daisy; 21) }\end{array}$ \\
\hline $\begin{array}{l}\text { Abstracting from } \\
\text { reflections (ELT3; } \\
\text { TL3; TL5; TL6) }\end{array}$ & $\begin{array}{l}\text { "It comes through some sort of awareness of what has happened and then you } \\
\text { have got to think of how you will change it when you are in a different type of } \\
\text { environment... I have got to simply say to myself: "this is how I will do it"“ } \\
\text { (Melissa; 27) } \\
\text { "The meaning of life is getting bigger; it is really difficult to explain. I was happy }\end{array}$ \\
\hline
\end{tabular}


Changing perspectives (ELT4; TL6; TL7; TL8; TL9)
Adapting behaviors (ELT4; TL7; TL8; TL9; TL10) with just the small things in my country but now I want to learn more about other things... meet more people and make my life happier..." (Ella; 21)

"[As an au pair], the kids rely on you and... because I was the only responsible adult, so I realized that I had to be responsible in a way that beneficial to the children and not for myself... [it is] a shift from focusing on yourself." (Whitney; 21)

"When I got to America I got a whole bunch of new friends, a girlfriend and I gradually become a lot more generous, a lot more free with spending [my money] and with spending time with other people." (Giovanni; 19)

"In Sydney, I was living in a one-man bachelor pad. That is when it started, I had this whole space to myself... with the atmosphere out there and the people... gradually, I just became more relaxed, more confident and organize myself."(Gabriel; 20)

"Well it was a forced change because when I was out there,... I was independent doing things on my own...things that I would have not normally have done, [like] I learnt how to cook... [but] since I have come back I haven't done a lot of cooking. It was just something that I did when I was out there." (Ulrich; 22)

"I was sort of there, I could not believe that I was actually doing it - just arrived in this crazy place. Yes, after the first two weeks I think I was coming to terms with what I was going to do... The first meal we made was disgusting so we like: 'Oh god - we will have to get a lot better and definitely a lot quicker and stuff like this'."(Gavin; 20)

"You just suddenly found yourself doing things that you didn't think that you would be able to do before... We didn't get along, it was like a learning curve to have to live and work with someone that you don't like... that was good because I hadn't learnt to deal with people like that before." (Charlotte; 20)

"I have totally changed my behavior... I didn't try to be someone else whereas my experience before I had to try to adapt to other people... I'm [no longer] afraid to make stupid jokes or to have any difficulties in my languages... if they don't accept me the way I am,... then I don't care I can make other friends" (Jessica; 22)

"Before I went I wouldn't have done anything around the house apart from lift[ing] my feet up so that my mum could hoover underneath! I do a lot more stuff around the house when I am there now. If I have been working I will still come home from work and cook a meal for everyone...." (Perry; 19)

"I am now doing different job. One of the things that I said to myself when I went away was that when I come back I want to move out of home. I sort of came back with goals whereas before I was just plodding along without really doing anything. So I think in that respect it has made me more focused." (Yves; 29)

* Note: abbreviations (e.g., ELT1, TL1, etc.) refer to Kolb and Mezirow stages (see Endnote for key) 
APPENDIX. Sample Characteristics

\begin{tabular}{|c|c|c|c|c|c|}
\hline Name & Residence* & Nationality/Ethnicity & Duration & Activities** & Destinations \\
\hline Perry & Essex & British (English) & $8 \mathrm{~m}$. & $\mathrm{T}$ & Australasia, N. America \\
\hline Giovanni & Brighton & British (English) & $3.5 \mathrm{~m}$. & $\mathrm{T}, \mathrm{W}$ & N. America \\
\hline Jessica & London & German (Chinese) & $6 \mathrm{~m}$ & $\mathrm{~T}, \mathrm{I}$ & Asia \\
\hline Dylan & London & British (English) & $1 \mathrm{yr}$. & $\mathrm{T}$ & Australasia, C. and S. America \\
\hline Rebecca & Godalming & British (Polish) & $1 \mathrm{yr}$. & $\mathrm{T}, \mathrm{W}$ & Australasia \\
\hline Chloe & Gloucestershire & British (English) & $4 \mathrm{~m}$. & $\mathrm{T}, \mathrm{W}$ & Australasia \\
\hline Keanu & London & British (Japanese) & 1 yr. $5 \mathrm{~m}$. & $\mathrm{T}, \mathrm{W}$ & N. America \\
\hline Brayden & London & British (Scottish) & $4 \mathrm{~m}$. & $\mathrm{T}$ & Africa, Europe \\
\hline Ella & Guildford & British (Korean) & $6 \mathrm{~m}$ & $\mathrm{~T}$ & Asia, Europe \\
\hline Gavin & Dorset & British (English) & $4.5 \mathrm{~m}$. & $\mathrm{T}, \mathrm{TE}$ & Asia \\
\hline Ethan & Godalming & British (English) & $1 \mathrm{yr}$. & $\mathrm{T}, \mathrm{W}$ & Australasia \\
\hline Kiefer & Guildford & British (English) & 1 yr. 3 m. & $\mathrm{T}, \mathrm{TE}$ & Australasia, Europe \\
\hline Melissa & Guildford & Bulgarian & $9 \mathrm{~m}$ & $\mathrm{~T}, \mathrm{I}, \mathrm{V}$ & Europe \\
\hline Ulrich & Guildford & British (English) & $1 \mathrm{yr}$. & $\mathrm{T}, \mathrm{I}$ & N. America \\
\hline Charlotte & Devon & British (English) & $8 \mathrm{~m}$. and $4 \mathrm{~m}$. & $\mathrm{T}, \mathrm{TG}$ & Africa, N. America \\
\hline Anna-Rose & Essex & British (English) & $6 \mathrm{~m}$ & $\mathrm{~T}, \mathrm{TG}$ & Africa, Australasia \\
\hline Daisy & Brighton & British (English) & $8 \mathrm{~m}$ & $\mathrm{~T}, \mathrm{~W}$ & Australasia \\
\hline Felicity & London & British (Indian) & $3.5 \mathrm{~m}$. & $\mathrm{I}, \mathrm{V}$ & Asia, Europe \\
\hline Whitney & Nottingham & British (English) & $7 \mathrm{~m}$ & $\mathrm{~T}, \mathrm{~W}$ & Europe \\
\hline Connor & Devon & British (English) & $6 \mathrm{~m}$ & $\mathrm{~T}$ & Asia \\
\hline Yves & Guildford & British (English) & 1 yr. 5 m. & $\mathrm{T}, \mathrm{W}$ & Asia, Europe \\
\hline Nicole & Sutton & British (English) & $5 \mathrm{~m}$ & $\mathrm{~T}$ & Africa, Asia, S. America \\
\hline Verity & London & Belgian & $5 \mathrm{~m}$ & $\mathrm{~T}$ & Australasia, N. America \\
\hline Naomi & London & Indian & $3 \mathrm{~m}$ & $\mathrm{~T}, \mathrm{~V}$ & Asia \\
\hline McKenzie & Glasgow & British (English) & $4 \mathrm{~m}$ & $\mathrm{~T}$ & Central and S. America \\
\hline Vivienne & London & Greek & $9 \mathrm{~m}$ & $\mathrm{~T}, \mathrm{~V}$ & Asia \\
\hline Gabriel & Hampton & British (S. African) & $7 \mathrm{~m}$. & $\mathrm{T}, \mathrm{W}$ & Australasia, Europe, N. America \\
\hline
\end{tabular}

Notes: * Residence at time of interview; ** T (travelling); W (working); I (internship); TE (teaching English); TG (teaching general); V (volunteering); V (visiting friends/family) 


\section{Interview Protocol}

1. Introduction (approximately 10 minutes)
a. Providing Information for the Participant Sheet
b. Signing Consent Form
c. Warming up: Filling in the background information about participants and their trip

2. Main Interview (between 30 - 60 minutes; depending on the information provided by the participants)
a. The main interview questions were as follows: b. What was the most significant experience during your gap year travel (GYT)? (this
question is to be repeated as necessary to elicit other significant experiences; the definition of 'significant' are left to the understanding of the participants)
c. Can you please tell me more about it?
d. What did $\underline{x}$ mean to you?
e. What does $\underline{x}$ mean to you now?
f. What was important about $\underline{\mathrm{x}}$ to you?
g. What do you think have changed for you as a result of that experience?
h. What have you discovered about yourself as a result of this experience?

3. Closing (approximately 5 minutes)

a. A brief summary of the interview.

b. Thanking the participant for their time and willingness to share.

\section{Endnote}

\footnotetext{
${ }^{1}$ We now offer a $\underline{A}$ word on experiential learning theory (ELT) and transformative learning (TL) conventions is necessary. Kolb (1984) modelled experiential learning as a four-stage cycle: concrete experience (abbreviated in Table 1 to 'ELT1', etc.); reflective observation (ELT2); abstract conceptualization (ELT3); active experimentation (ELT4). Mezirow $(1991,2000)$ modelled transformative learning as ten 'typical' (Nohl, 2015: 36) phases: A disorienting dilemma (abbreviated in Table 1 to 'TL1', etc.); Self-examination with feelings of fear, anger, guilt or shame (TL2); A critical assessment of assumptions (TL3); Recognition that one's discontent and process of transformation are shared (TL4); Exploration of options for new roles, relationships, and actions (TL5); Planning of a course of action (TL6); Acquiring knowledge and skills for implementing one's plans (TL7); Provisional trying of new roles (TL8); Building competence and self-confidence in new roles and relationships (TL9); A reintegration into one's life on the basis of conditions dictated by one's new perspective (TL10) (Mezirow, 2000, p. 22). NB: for brevity we use the codes in brackets when referring to the components of experiential learning theory (ELT1-4) and transformative learning theory (TL1-10) in the data analysis (see below).
} 